\title{
The contamination of intravenous fluids by writing on the infusion bag: Fact or fiction?
}

\author{
James D. Langston ${ }^{1}$, W. Patrick Monaghan ${ }^{1}$, Melissa Bush ${ }^{2}$ \\ ${ }^{I}$ Nurse Anesthesia Program Brooks College of Health University of North Florida \\ ${ }^{2}$ Department of Chemistry, Science and Engineering University of North Florida \\ Corresponding author E-mail: N00653699@ospreys.unf.edu
}

\begin{abstract}
Introduction -Laboratory experiments were conducted to ascertain whether Sharpie ${ }^{\circledR}$ brand black permanent marker ink will permeate through intravenous infusion bags. The practice of writing directly on infusion bags is a frequent yet controversial practice. There are no known written standards that exist which pertain to this practice.

Methods - Five types of intravenous bags containing different solutions marked with black ink from a fine point felt tipped Sharpie ${ }^{\circledR}$ marker. Sample extraction occurred after infusion bags had been warmed to $40 \mathrm{C}$ or remained ambient. Spectrophotometric scans and measurements were conducted at 300 to $600 \mathrm{NM}$ on each solution contained in the experimental bags. Writing with Sharpie ${ }^{\circledR}$ pens on filter paper and surgical tape was also conducted.

Results - A total of 17 experiments were conducted with intravenous bags of five different types of manufacture. There appeared to be no visible or ultraviolet spectrophotometric evidence of leaching of the ink from Sharpie ${ }^{\circledR}$ pens. Four different lot numbers of Sharpie ${ }^{\circledR}$ pens were used. Surgical tape that was written on using Sharpie ${ }^{\circledR}$ markers readily exhibited visible evidence of permeability.

Discussion - The experiments conducted would appear to indicate that the infusion containers tested maintained an intact barrier to the application of Sharpie $\AA$ brand permanent marker ink. Writing on surgical tape does not stop the permeability of Sharpie ${ }^{\circledR}$ pens. This study could serve as a suitable pilot study for others to conduct a much more comprehensive study using a greater number of intravenous containers, solutions and ink markers.
\end{abstract}

Keywords: Fluid therapy, infusion, ink, intravenous, writing.

\section{Introduction}

The act of writing directly on infusion bags is a controversial practice among many healthcare providers. For many years it has been thought to be an erroneous act that may impart harm to the patient, but no recent scientific study has been done to clarify this activity. The act of writing on an infusion bag with a Sharpie® felt tip marker has in the past been construed as a patient safety issue. However, there are no known written standards that exist which pertain to the advocacy or banning of this practice. It is the position of the Infusion Nurses Society that writing on an intravenous bag may cause ink to leach into the bag and contaminate the infusate (C. Scarpon, personal communication, May 18, 2012). The Institute of Safe Medical Practices in three separate newsletters does not endorse or condone the application of ink directly on IV flexible plastic containers [1], [2]. "The application of ink from magic marker or other writing tools has not been tested for safe use on IV bags; thus volatile chemicals in the ink may reach the solution to be intravenously infused" [3].

After an extensive literature review, the last study of this type was done in 1989 by Bickler and associates using felt tip markers and PVC infusion bags. Bickler and associates concluded that only "trivially small quantities of ink could penetrate the PVC barrier" (Bickler, et al.1989, p. 412) [4]. Since then, the methods of manufacturing infusions bags have markedly changed. In 1989, most if not all infusion bags were made from polyvinyl chloride (PVC). In 1999, it was discovered that Diethylhexyl (DETH) phthalate plas- ticizers were leaching into the reservoir of fluids resulting in impaired renal and hepatic function as well as toxicity to the male reproductive system [5]. This situation forced manufactures to change their production methods to produce a phthalate plasticizer free product. As a result of this history and of these developments; a bench study was produced to ascertain whether Sharpie ${ }^{\circledR}$ brand black permanent marker ink will particular leach through this new generation of intravenous infusion bags.

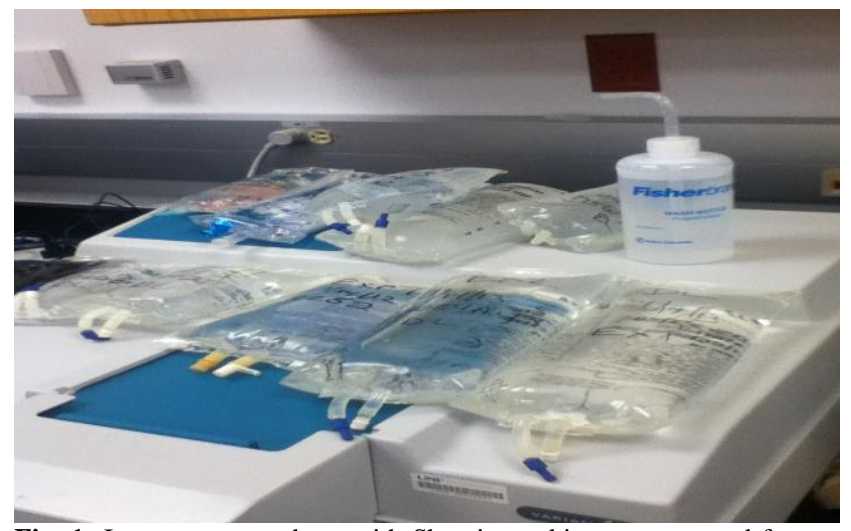

Fig. 1: Intravenous test bags with Sharpie markings prearranged for testing. 


\section{Methods}

A bench study was formulated to examine five types of intravenous bags containing different intravenous solutions which were marked with black ink from a felt tipped fine point Sharpie ${ }^{\circledR}$ marker. Both positive and negative control intravenous bags were utilized. (Figure 1) The laboratory experiments were conducted at ambient temperature and at $40^{\circ} \mathrm{C}$ over a 24 hour period. The 24 hour time limit was selected due to it being the standard maximum "hang time" of all infusing intravenous fluids as per the Infusion Nurses Society (C. Scarpon, personal communication, May 18 , 2012). Both visible and ultraviolet spectrophotometric scans and measurements were conducted between 300 to $600 \mathrm{NM}$ with a Perkin Elmer Lambda ${ }^{\circledR} 35 \mathrm{UV} / \mathrm{V}$ is spectrometer. The standard deviation (SD) for this spectrometer is 0.05 nanometers (NM).Calibration was done prior to specimen analysis and fell within 2 SD. The known wavelength peaks for black Sharpie ${ }^{\circledR}$ ink are $373 \mathrm{NM}, 438 \mathrm{NM}, 567 \mathrm{NM}$ and $586 \mathrm{NM}$ per direct inquiry of Newell Rubbermaid Office Products (B. Kelly, personal communication, September 6, 2012). A total of four separate lots of black Sharpie ${ }^{\circledR}$ permanent markers were used in this study. Each intravenous solution contained in the experimental bags was specifically analyzed for known wavelengths for black Sharpie ${ }^{\circledR}$ fine point markers. The specific infusion containers analyzed were: Baxter polyvinyl chloride laminate \#146; Hospira VisIV® and Freeflex ${ }^{\circledR}$; and B. Braun Excel ${ }^{\circledR}$ system. Baxters's VIAFLEX ${ }^{\circledR}$ and VIAFLEX.Plus ${ }^{\circledR}$ plastic infusion containers fabricated from a specially formulated polyvinyl chloride. Hospira VisIV® is a multilayer film of thermoplastics that include polypropylene and other polyolefins. Additionally, Hospira's hetastatch $6 \%$ in $0.9 \%$ sodium chloride solution is contained within the Freeflex ${ }^{\circledR}$ reservoir and manufactured with a coextruded polyolefin. The Excel ${ }^{\circledR}$ system from B. Braun uses an Ecdel ${ }^{\circledR}$ elastomer resin developed by Texas Eastman that is a combination of polypropylene and polyolefin resins into a co-polyester ether resin. Braun uses this Ecdel ${ }^{\circledR}$ elastomer resin to manufacture its infusion containers. B. Braun and Hospira manufacturing methods utilize multilayer films via thermal bonding of the copolymer of ethylene and/or polyolefin and polypropylene allow for a product that is autoclavable [6]. The experimental infusion bags were exposed to the black Sharpie ${ }^{\circledR}$ ink at 15 minutes, 1 hour, 4 hours and 24 hours. One tested specimen was initially warmed to 40 degrees Celsius in a water bath then the external bag was removed and the specimen was immediately marked (experiment \# 3) for a period of 24 hours. Specimen in experiment \#4 was completely covered in ink for 24 hours. Additionally several empty bags were opened and Whatman ${ }^{\circledR}$ filter paper (catalog \# 1442-055) was inserted. Afterward the external portion of the infusion bag was liberally marked with a random Sharpie ${ }^{\circledR}$ marker from one of the four lots. These experimental bags were placed under approximately 20 pounds of pressure to ensure constant contact between the IV bag \& filter paper. This was maintained for 24 hours at ambient temperature. Finally $3 \mathrm{M}$ type surgical silk tape was also marked with a random Sharpie ${ }^{\circledR}$ as well. Filter paper was applied to the adhesive side of the tape for a period of 24 hours at ambient temperature.

\section{Results}

A total of 17 experiments were conducted with intravenous bags, solutions and surgical tape. There appeared to be no visible or spectrophotometric evidence of leaching of the ink from Sharpie ${ }^{\circledR}$ marked infusion bags into the intravenous solutions. Macroscopic examination of the filter paper inserted into the empty bags revealed no evidence of ink. However the black Sharpie ink readily permeated the surgical silk tape. These experiments included 14 different intravenous bags with five different methods of manufacture. A variety of solutions were used with most being $0.9 \%$ sodium chloride solution (65\%), Lactated Ringers solution USP (14\%), $6 \%$ hetastarch in $0.9 \%$ sodium chloride, $(7 \%)$, dobutamine premixed in $5 \%$ dextrose solution, $(7 \%)$ and Plasma-Lyte $A \circledR$ solution (7\%). Four different lot numbers of Sharpie® pens were used in this study. Surgical tape that was written on using Sharpie ${ }^{\circledR}$ markers readily exhibited visible evidence of permeability through the $3 \mathrm{M}$ silk tape via use of Whatman ${ }^{\circledR}$ filter paper.

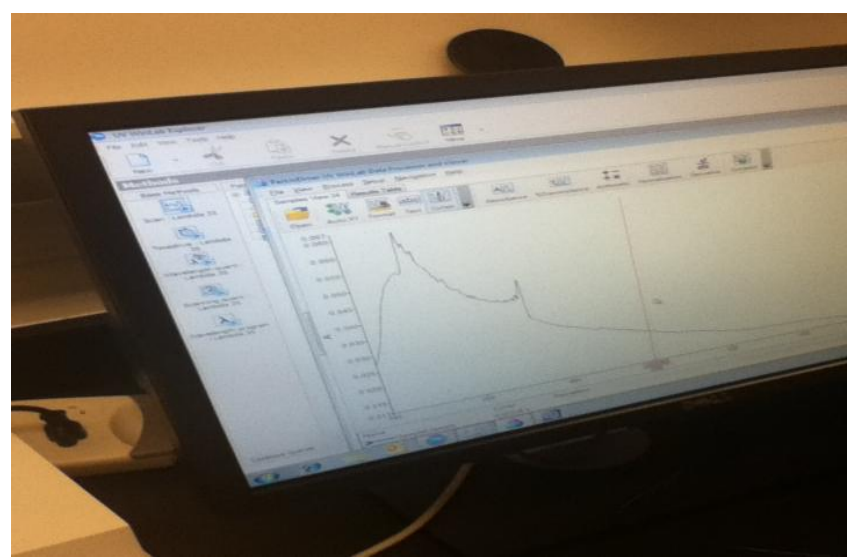

Fig. 2: Peak wavelengths indicative of sodium chloride solution noted. No activity at known wavelengths (373NM, 438MN, 567MN, and 586MN) of targeted black Sharpie $®$ ink noted

\section{Discussion}

This research was presented in part at the American Association of Nurse Anesthetists National Congress in Las Vegas, Nevada from August 10-12, 2013. A great deal of interest was demonstrated by a high volume of visiting personnel and positive interaction with participants of the conference. The experiments conducted would appear to indicate that all the infusion containers tested maintained an intact barrier to the application of Sharpie ${ }^{\circledR}$ brand permanent marker ink. The failure of any ink solvents or volatile to permeate any of the experimental infusion containers may suggest the modern IV bags are sufficiently impermeable to black Sharpie ink. Furthermore, the convenience of writing directly on the bags should not be discouraged for fear of polluting the solution. Writing on surgical tape does not stop the permeability of Sharpie ${ }^{\circledR}$ pens. The results of this study could serve as a suitable pilot study for others to conduct a much more comprehensive study using a greater number of intravenous containers, solutions and/or ink markers. Limitations of this study include limited number of infusion containers and limited methods of testing. The findings of this study suggest that no leaching of black ink from Sharpie markers occurs when currently manufactured intravenous bags are manually labeled.

\section{References}

[1] Safety Briefs. (2004, February 12). Institute for Safe Medication Practices - Medication Safety Alert Newsletter, P. 2-3. Retrieved from http://www.ismp.org/Newsletters

[2] Safety Briefs. (2004, July 15). Institute for Safe Medication Practices Medication Safety Alert Newsletter, P. 2. Retrieved from http://www.ismp.org/Newsletters.

[3] Safety Briefs. (2002, May 29). Institute for Safe Medical Practices Medication Safety Alert, P. 2. Retrieved from http://www.ismp.org/Newsletters.

[4] Bickler, P. E., Gold, B., \& Johnson, B. H. (1989). Diffusion of FeltTip Marker Pen Ink into Intravenous Bags. Anesthesia \& Analgesia, 69, 412. Retrieved from http://www.anesthesia-analgesia.org/

[5] Hospitals Health Care without Harm - Preventing Harm from Phthalates, Avoiding PVC in Hospitals, 4-27. Retrieved from http://www.pehsu.org/research/hsostenible/dehp/detailsdehp.pdf.

[6] Alternatives to PVC for IV bags. (2002, April 18). Pharmaceutical and Medical Packaging News. Retrieved from www.pmpnews.com. 